\title{
Analysis of Blast Fragmentation Using WipFrag
}

\author{
Suryajyoti Nanda \\ Student of Mining engineering department, \\ National Institute of Technology, Rourkela, India
}

\begin{abstract}
Fragmentation is the process of breaking of solid in-situ rock mass into several smaller pieces which are being excavated or moved by material handling equipment. It is the major concern of any blasting operation. Information on the degree and size distribution of fragments within a blasted rock mass is essential for efficient loading, transport, crushing and milling operations. An automated image based granulometry system WipFrag is used to analyze the digital image of rock photographs to determine grain size distribution. The method was tested in Dongri Buzurg open-pit manganese mine of Maharashtra (India). WipFrag software was found to be useful for fragmentation analysis of blast fragment sizes in very short interval of time.
\end{abstract}

Keywords:- WipFrag, Fragmentation, Blasting, Uniformity Coefficient, Coefficient of Gradation.

\section{INTRODUCTION}

Rock Fragmentation is one of the major concern of any mining industry, which affects the financial part of the industry quite heavily. The efficiency of the downstream mineral processing and comminution process is greatly dependent on the post-blast rock size distribution. Optimal fragmentation reduce the cost of production and that can be achieved by properly designed blasting pattern [1]. If the fragment size is higher than requirement that will negatively affect the efficiency of loading and hauling equipments and ultimately leads to secondary blasting which will add to financial part of the mine. It will also increase the frequency of sorting of oversize boulders which will affect the productivity of the mines. Similarly, fine size materials also create undesirable situations in the mine because that involves extra consumption of explosives, which will definitely add to the overall cost of mining. Fragmentation of the quarries or rock is a result of blasting operations and that is said to be optimum if it contains maximum percentage in desired range of size [2]. There are many controllable and uncontrollable parameters, which directly or indirectly affects rock fragmentation. Optimum rock fragmentation can be achieved by optimizing the controllable parameters and should be designed in such a manner that the uncontrollable parameters do not affect the fragmentation much. The controllable parameters for optimizing the rock fragmentation can be changed after induction of trial blasts in a mine and then the mine officials can fix the optimized parameters. When we measure the parameters for the optimization of rock fragmentation and then modify them, the process is called Quantification and by this process we get almost optimized fragmentation in any blasting site [3].
B.K. Pal

Faculty of Mining engineering department, National Institute of Technology, Rourkela, India

\section{FRAGMENTATION MEASUREMENT TECHNIQUES}

Quantification of fragmentation on a large scale is an extremely complicated task and extensive research has been carried out with different methods and tools for measurement of fragmentation. Conventional methods for measurement of fragmentation include sieving or screening, over-size boulder count method and shovel loading rate method. Modern techniques include visual analysis method, photogrammetric method and image analysis method.

\section{$>$ Sieving or Screening}

Sieving or Screening is a direct and accurate method of evaluation of size distribution of particles or fragmentation. This method is feasible in small scale blasts or operations but it involves cost and time consuming. Rock fragments are screened through different sieves of different mesh numbers for different fragment sizes and the screened out fragments are grouped according to their size. The nature of blast is predicted by counting the number of fragments in each size [4].

\section{Oversize boulder count method}

In this method, an Oversize index is calculated based on oversize boulders, which cannot be hauled or processed, by shovels or any machinery that is used by mine. The index is calculated with respect to the total blasted in-situ mass [5].

\section{Shovel loading rate method}

This method is more accurate for comparative account of the nature of fragmentation of a group of blasts. This method assumes that the faster the mucking the better the fragmentation. The loading rate of a shovel is taken into consideration [6]. This method is not efficient when there is no uniform fragment distribution containing maximum percentage of undersize fragments.

\section{Visual analysis method}

In this method, the post-blast muck is viewed immediately after the blasting by the mining professionals and the decision is taken whether to go for secondary blasting or to change the parameters to optimize the rock fragmentation. This is a subjective assessment method and cannot be trusted completely as the superficial view of the fragments do not give data about the hidden portion [7].

\section{Photogrammetric method}

This method is more reliable and accurate as it can provide three dimensional measurements to calculate the fragmentation volume [8]. 


\section{$>$ Image analysis method}

Digital image processing systems are becoming increasingly employed in every industrial applications, not just in research. With the advancement of inexpensive fast computing power, improved image processing techniques and algorithms, and the availability of inexpensive, portable and light-sensitive video cameras, sizing of materials is now becoming routine [9]. There are various advantages of image analysis over conventional methods:

- Image processing is accurate, less time consuming and multiple images can be analyzed simultaneously.

- Image processing does not disrupt or interfere in the production process.

- Image processing is inexpensive and sampling errors are less significant.

\section{$>$ Kuz-Ram model for the calculation of fragmentation}

Cunningham developed the Kuz-Ram empirical model in the 1980s [10] to determine the mean fragmentation size of a blast which is given as:

$$
X=A \times\left(\frac{V}{Q}\right)^{0.8} \times(Q)^{0.167} \times\left(\frac{E}{115}\right)^{-0.633}
$$

(Equation 1)

Where,

$\mathrm{X}=$ Mean fragment size, $\mathrm{cm}$

$\mathrm{V}=$ Volume of blasted rock, $\mathrm{m}^{3}$

$\mathrm{Q}=$ Mass of explosive charge per hole, $\mathrm{kg}$

$(\mathrm{ANFO}=100)$

$\mathrm{E}=$ Weight strength relative to ANFO considering

$\mathrm{A}=$ Rock factor (varying between 0.8 and 22, depending on hardness and structure)

\section{Uniformity Coefficient $\left(C_{u}\right)$}

On the basis of great number tests with filter sands, Hazen (1892) found uniformity coefficient which is a convenient mechanical analysis to express the grain-size characteristics of soil that indicate the dominant soil fraction [11].

\section{$\mathrm{C}_{\mathrm{u}}=\mathrm{D}_{60} / \mathrm{D}_{10}$}

Where,

$\mathrm{D}_{60}$ is the grain size corresponding to $60 \%$ of the sample passing by weight

$\mathrm{D}_{10}$ is the grain size corresponding to $10 \%$ of the sample passing by weight

\begin{tabular}{|c|c|}
\hline $\mathbf{C}_{\mathbf{u}}$ & Grain size characteristics \\
\hline $\mathrm{C}_{\mathrm{u}}<5$ & very uniform \\
\hline $\mathrm{C}_{\mathrm{u}}=5-15$ & medium uniform \\
\hline $\mathrm{C}_{\mathrm{u}}>15$ & non uniform \\
\hline
\end{tabular}

Table 1:- $\mathrm{C}_{\mathrm{u}}$ and Grain size characteristics

\section{Coefficient of Gradation $\left(C_{g}\right)$}

Coefficient of Gradation is used t0 measure the shape of the particle size curve. $C_{g}$ around 1-3 indicates the distribution of fragments [12].

$$
\mathrm{C}_{\mathrm{g}}=\left(\mathbf{D}_{30}\right)^{2} /\left(\mathbf{D}_{60}\right) *\left(\mathbf{D}_{10}\right)
$$

\section{IMAGE ANALYSIS USING WIPFRAG}

The WipFrag image analysis software uses the technique of analysis of digital image of the blasted rock with granulometry system to predict the grain size distribution in the muck pile [9]. A camcorder conducts 2D post-processing of image data i.e. acquiring the images of the muck pile in the field. A scale device is used in each view to reference the sizing. The photographs of the muck pile is taken from different angles and then the image is transferred to the computer in which WipFrag is installed. The broken rock image is transformed into a particle map or network. Network areas are converted into volumes and weights and the resulting data is displayed as a graph. The fidelity and speed of fragment edge detection allow fully automatic remote monitoring at a rate of one image per 3 to 5 seconds. WipFrag can also compare the net generated pic of the muckpile with the original rock image. The fragment boundaries are analyzed efficiently using Edge Detection Variables (EDV). For better accuracy, the edges of the rocks can also be improved manually.

\section{EXPERIMENTAL SITE DETAILS}

Mining leases of Dongri Buzurg mine are located in the village Dongri Buzurg, Balapur Hamesha and Kurmuda in Tumsar Tahsil under Bhandara district of Maharashtra state. Dongri Buzurg mine is located in the North Eastern part of Bhandara district, in the state of Maharashtra and it is about $120 \mathrm{Kms}$ from Nagpur.

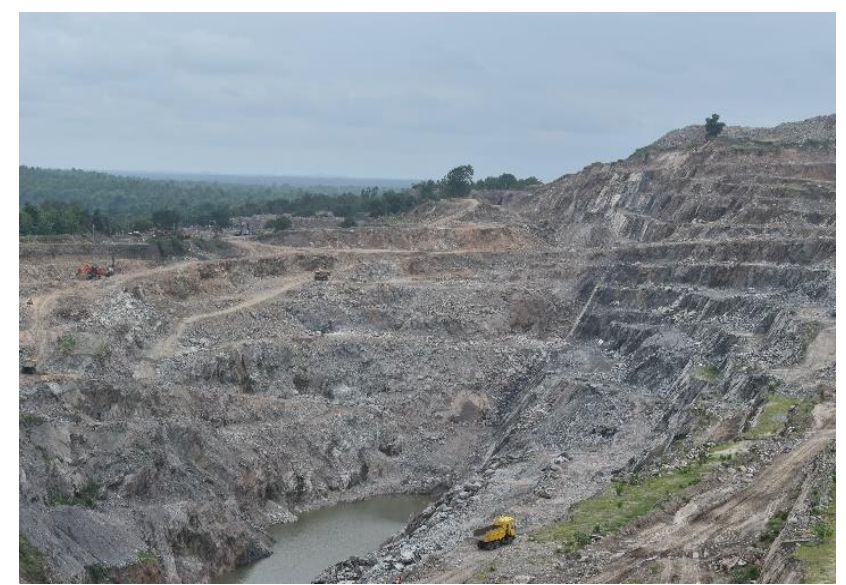

Fig 1:- Overview of Dongri Buzurg Mine, MOIL, India.

The manganese ore horizon occurs as a continuous bed at the stratigraphic contact of overlying Sitasaongi formation and the underlying Munsar formation, on the reversed limb of a regional anticline within the Balapur Hamesha lease hold area of the mine. 
The ore horizon is traceable over a length of $2150 \mathrm{~m}$ trending $\mathrm{E}-\mathrm{W}$ in the eastern and central part and ENEWSW in the western part with moderate to steep southerly dips. Out of this $2150 \mathrm{~m}$ strike length, only $260 \mathrm{~m}$ is in Kurmuda portion, and remaining $1890 \mathrm{~m}$ is within Balapur Hamesha lease area. The thickness of the manganese ore horizon varies from 2 to $30 \mathrm{~m}$. It is thickest in the central part and gradually tapers down to about $2 \mathrm{~m}$ at both ends. Towards the western end of Balapur Hamesha lease, the Manganese ore horizon bifurcates into two thin bends separated from each other by Sitasaongi schist. The southern band extends westward for about $190 \mathrm{~m}$. The northern band continues westward with the strike veering gradually towards South, and broadens to about $10 \mathrm{~m}$ before entering Kurmuda.

The manganese ore deposits are of syngenetic metasedimentary, bedded type, which have been regionally metamorphosed. At Dongri Buzurg the deposit has been further acted upon by circulating water, resulting in conversion of lower oxides to higher oxides at normal temperature \& pressure. In the central part the manganese ore body is completely oxidized and enriched over a strike length of $1000 \mathrm{~m}$ to $1200 \mathrm{~m}$. The ore minerals are Pyrolusite, Psilomelane, Cryptomelane and Hausmannite. Due to leaching action on gondite, quartz partings have been leached out and cavities of different shapes and sizes were developed with range in size from $0.5 \mathrm{~mm}$ to $3 \mathrm{~m}$ across and are mostly interconnected. These cavities are lined with Pyrolusite crystals/crystalline silica. The secondary manganese ores occur as crystalline aggregate, botryoidally, acicular, columnar and amorphous form. In the West hill and as well as in the East hill section the leaching effect is not prominent and is observed only up to shallow depth.

The manganese ore body at Balapur Hamesha area is traceable over a strike length of $1890 \mathrm{~m}$. Of this, in the western portion of $800 \mathrm{~m}$ strike length, the thickness of the manganese ore horizon ranges between $2.5 \mathrm{~m}$ to $4 \mathrm{~m}$. However at the western end of lease, the width increases to $10 \mathrm{~m}$ and continues so in the Kurmuda block. The manganese ore horizon trends ENE-WSW with steep southerly dips. The ore body at the mid segment has been worked up to 277 MRL by opencast, where as in the western $\&$ eastern section the deposit was earlier opened by underground level. The eastern $660 \mathrm{~m}$ strike length of the ore body trends EW with moderate to steep southerly dips. The thickness of the ore body varies generally from $2 \mathrm{~m}$ to $8 \mathrm{~m} \&$ at some place less than a meter approx. The ore body has been worked out by both opencast and underground methods.

\section{Mining technology}

Considering the mineralisation \& disposition of manganese ore, it has been proposed to work with diesel hydraulic shovel and rear dumper combination. Horizontal slicing method of mining has been adopted in this mine for both extraction of ore and development. A diesel hydraulic back hoe in combination with existing $35 \mathrm{~T}$ rear dumper and diesel hydraulic back hoe in combination with $60 \mathrm{~T}$ rear dumper have been proposed. Drill hole diameter of $110 \mathrm{~mm}$ has been proposed for muck generation and 320 HP Dozers are proposed for bench preparation. Auxiliary equipment has also been proposed to ease the mining operations. The mining parameters are shown in table 2 .

\begin{tabular}{|c|c|}
\hline Mining Parameters & Size/Description \\
\hline Mining method & $\begin{array}{c}\text { Opencast: Shovel dumper } \\
\text { combination }\end{array}$ \\
\hline Recovery factor & $80 \%$ \\
\hline Mining loses & $\begin{array}{c}\text { Skin ore around 0.5m (overall } \\
3 \% \text { ) }\end{array}$ \\
\hline Cutoff grade & $25 \% \mathrm{Mn}$ \\
\hline Ultimate pit depth & $205 \mathrm{MRL}$ \\
\hline Height of Bench & $10 \mathrm{~m}$ \\
\hline Working bench width & $20 \mathrm{~m}$ \\
\hline Non-working bench \\
width & $12 \mathrm{~m}$ \\
\hline Bench slope & $70^{\circ}$ \\
\hline Overall pit slope & $32^{\circ} / 33^{\circ}$ \\
\hline Stripping Ratio & $1: 9$ \\
\hline
\end{tabular}

Table 2:- Mining parameters at Dongri Buzurg mines,

(MOIL)

\section{$>$ Drilling and blasting}

Bieniawski's rock mass rating (RMR) in the mine is varying between 24 and 70, signifying poor to good rock mass conditions. Drilling is proposed to be done by means of drills with $110 \mathrm{~mm}$ hole diameter. Existing blast practices involves use of detonating fuse initiation with cord relay delay detonators and NONEL's using mainly Emulsion explosive. The usual blast pattern is spacing at $2.5 \mathrm{~m}$ and burden at $2.0 \mathrm{~m}$ with charge factor at $0.4 \mathrm{~kg} / \mathrm{m}^{3}$ for the ore body. Blasting in ore benches should produce uniform fragmentation without oversize. In view of this, blasting pattern of $2.5 \mathrm{~m}-2.0 \mathrm{~m}$ appeared to be optimum with bottom hole initiation. If lumps are required, a pattern of $3.0 \mathrm{~m} \mathrm{x}$ $2.5 \mathrm{~m}$ (spacing $\mathrm{x}$ burden) may be adopted with charge factor of $0.41 \mathrm{~kg} / \mathrm{m}^{3}$. A zone of weakness and joints often causes irregular fragmentation. Any explosive loaded in the zone of weakness will follow the line of least resistance and blow out causing larger size fragmented rocks.

\section{METHODOLOGY}

In this paper, three images are taken at different angles of a muck pile whose specifications are given in table 1. Using WipFrag image analysis software the photographs are analyzed in a system. The analysis of photographs is carried out using single image and multiple image analysis techniques. The mean size distribution is obtained from single image analysis technique and multiple image analysis technique is used for optimum rock fragmentation. The results of the individual single image analysis are shown in corresponding sample photographs. Single image analysis will provide only the cumulative rock size using WipFrag. As the digital images used for 
analysis cannot reveal the conditions of fragmentation behind the muckpile surface the results obtained from the individual analysis of the rock pile samples cannot be treated as perfect. Hence, an average result of the analysis is carried out. The results thus obtained would be much precise to predict the optimum blast parameters. Uniformity coefficient and coefficient of gradation is calculated for better understanding of blast fragment distribution.

\begin{tabular}{|c|c|}
\hline Blast Parameters & Size/Description \\
\hline Date & $21 / 7 / 18$ \\
\hline Bench Height & $10 \mathrm{~m}$ \\
\hline No. of Holes & 34 \\
\hline Type of explosive & Emulsion \\
\hline Charge & Primer \\
\hline Charge/holes & $2.78 \mathrm{~kg}$ \\
\hline Charge factor & $0.4 \mathrm{Kg} / \mathrm{m}^{3}$ \\
\hline Diameter of hole & $100 \mathrm{~mm}$ \\
\hline Burden & $2.5 \mathrm{~m}$ \\
\hline Spacing & $3 \mathrm{~m}$ \\
\hline Blast Pattern & Staggered (Toe Blast) \\
\hline Depth/Length of hole & $3 \mathrm{~m}$ \\
\hline Total charge & $94.5 \mathrm{Kg}$ \\
\hline No. of rows & 2 \\
\hline No. of columns & 17 \\
\hline Stemming Length & $2.5 \mathrm{~m}$ \\
\hline
\end{tabular}

Table 3:- Blasting parameters

\section{ANALYSIS OF DATA}

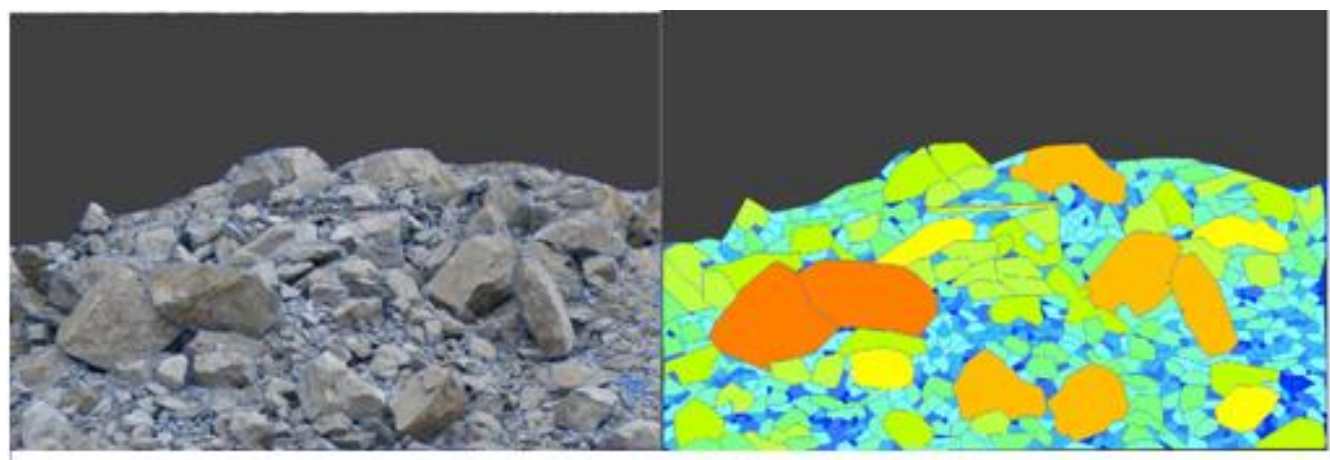

WipFrag 2.7.28 REE Division - CSIR-CMMFR - 2100952182 Saiket August 01, 2018, 02:31:15 PM india Standard Time

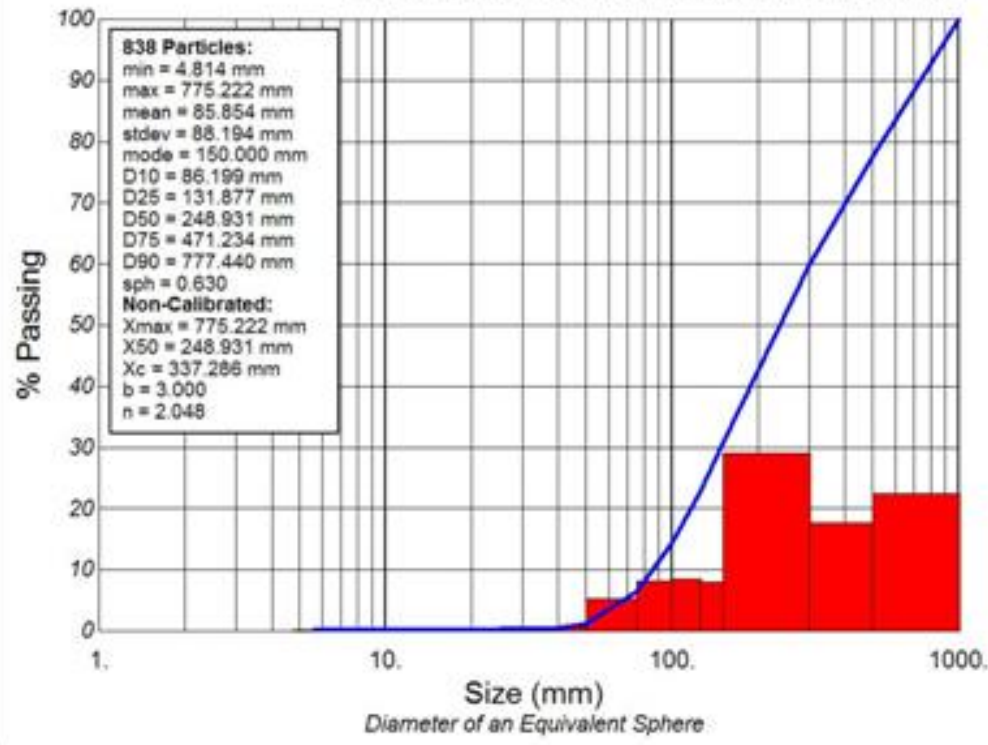

$\begin{array}{rr}\text { Size }(\mathrm{mm}) & \text { \% Passing } \\ 1000.00 & 100.00 \% \\ 500.00 & 77.53 \% \\ 300.00 & 59.92 \% \\ 150.00 & 30.79 \% \\ 125.00 & 22.80 \% \\ 100.00 & 14.45 \% \\ 75.00 & 6.39 \% \\ 50.00 & 1.10 \% \\ 40.00 & 0.49 \% \\ 37.50 & 0.40 \% \\ 35.50 & 0.32 \% \\ 31.50 & 0.24 \% \\ 25.00 & 0.17 \% \\ 16.00 & 0.08 \% \\ 12.50 & 0.05 \% \\ 10.00 & 0.04 \% \\ 8.00 & 0.03 \% \\ 6.70 & 0.02 \% \\ 5.60 & 0.02 \% \\ 4.75 & 0.00 \% \\ 4.00 & 0.00 \% \\ 3.35 & 0.00 \% \\ 2.00 & 0.00 \% \\ 1.40 & 0.00 \% \\ 1.00 & 0.00 \% \\ 0.85 & 0.00 \% \\ 0.60 & 0.00 \%\end{array}$

Fig 2:- Netting, contouring, histogram and cumulative size curve view of fragmented block at Dongri Buzurg Mine, MOIL, India. 
ISSN No:-2456-2165

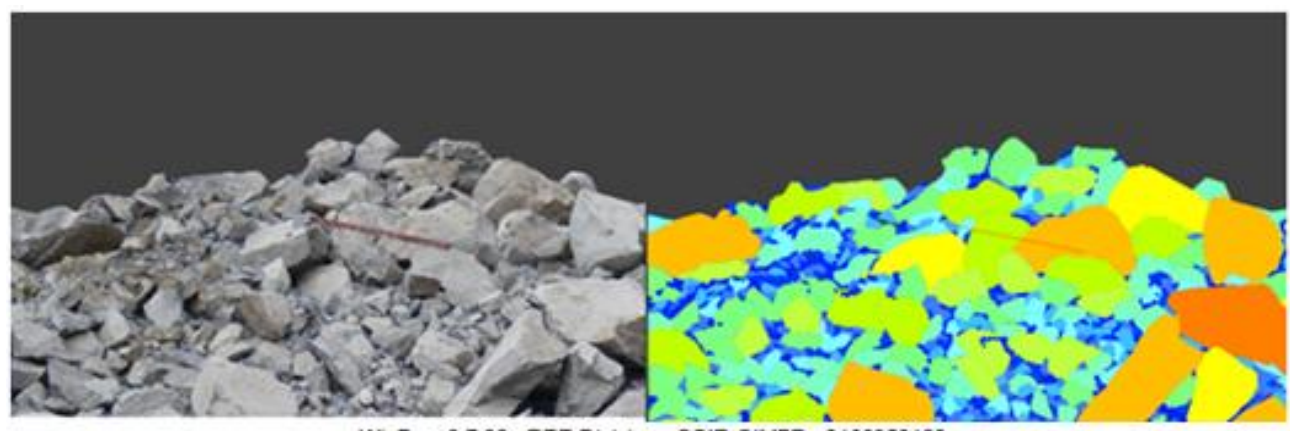

WipFrag 2.7.28 REE Owision - CSIR-CIMFR - 2100952182

DSC_0058 NIT ROUERKELA September 10, 2018, 05:54:18 PM india Standard Time

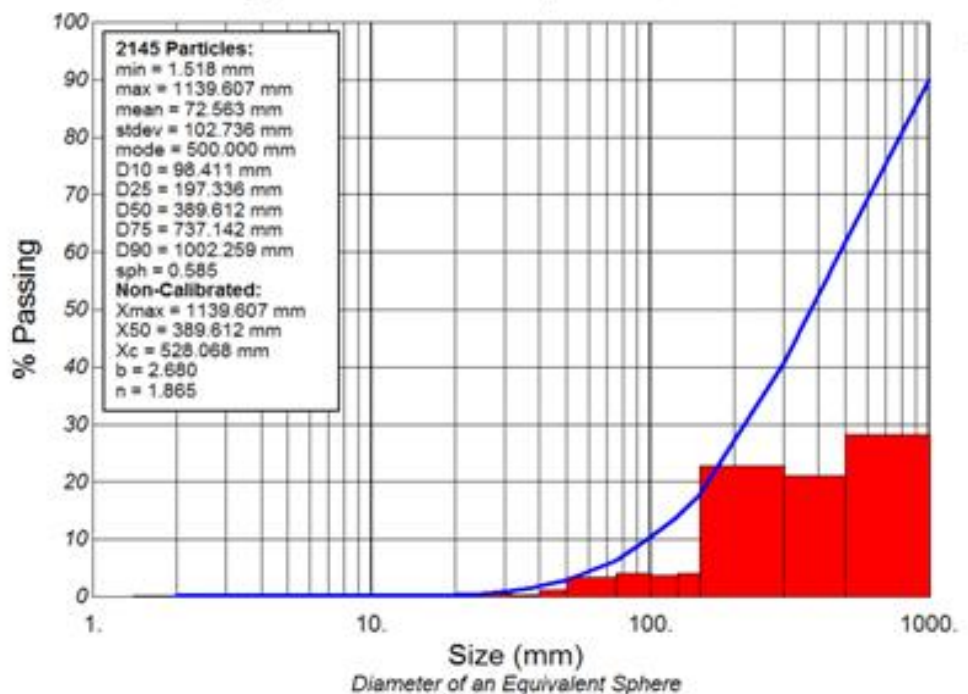

$\begin{array}{rr}\text { Size (mm) } & \text { \% Passing } \\ 1000.00 & 89.84 \% \\ 500.00 & 61.62 \% \\ 300.00 & 40.57 \% \\ 150.00 & 17.82 \% \\ 125.00 & 13.89 \% \\ 100.00 & 10.25 \% \\ 75.00 & 6.25 \% \\ 50.00 & 2.89 \% \\ 40.00 & 1.79 \% \\ 37.50 & 1.54 \% \\ 35.50 & 1.34 \% \\ 31.50 & 0.98 \% \\ 25.00 & 0.43 \% \\ 16.00 & 0.08 \% \\ 12.50 & 0.02 \% \\ 10.00 & 0.01 \% \\ 8.00 & 0.00 \% \\ 6.70 & 0.00 \% \\ 5.60 & 0.00 \% \\ 4.75 & 0.00 \% \\ 4.00 & 0.00 \% \\ 3.35 & 0.00 \% \\ 2.00 & 0.00 \% \\ 1.40 & 0.00 \% \\ 1.00 & 0.00 \% \\ 0.85 & 0.00 \% \\ 0.60 & 0.00 \% \\ & \end{array}$

Fig 3:- Netting, contouring, histogram and cumulative size curve view of fragmented block at Dongri Buzurg Mine, MOIL, India.

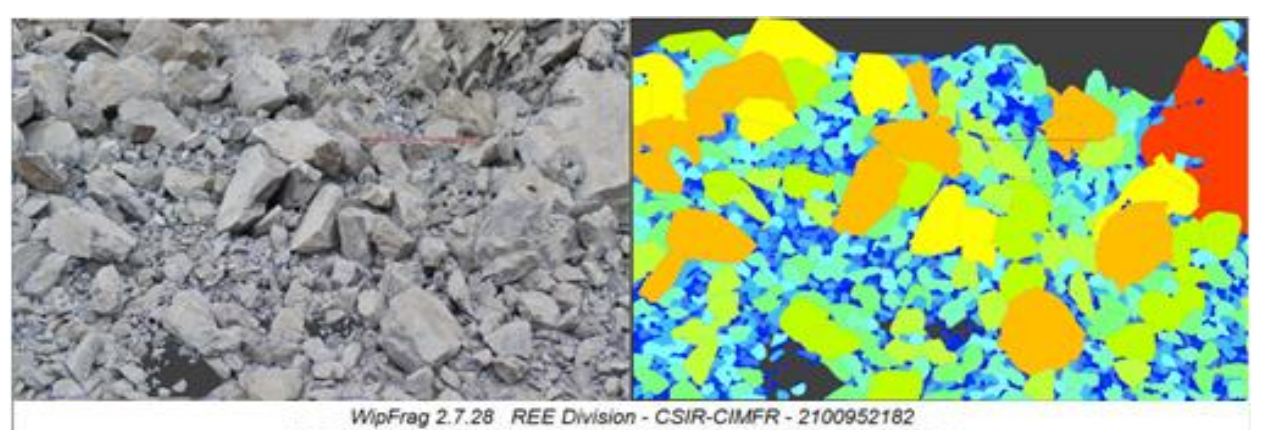
DSC_0055rouerkela August 31, 2018, 04:28:28 PM india Standard Time

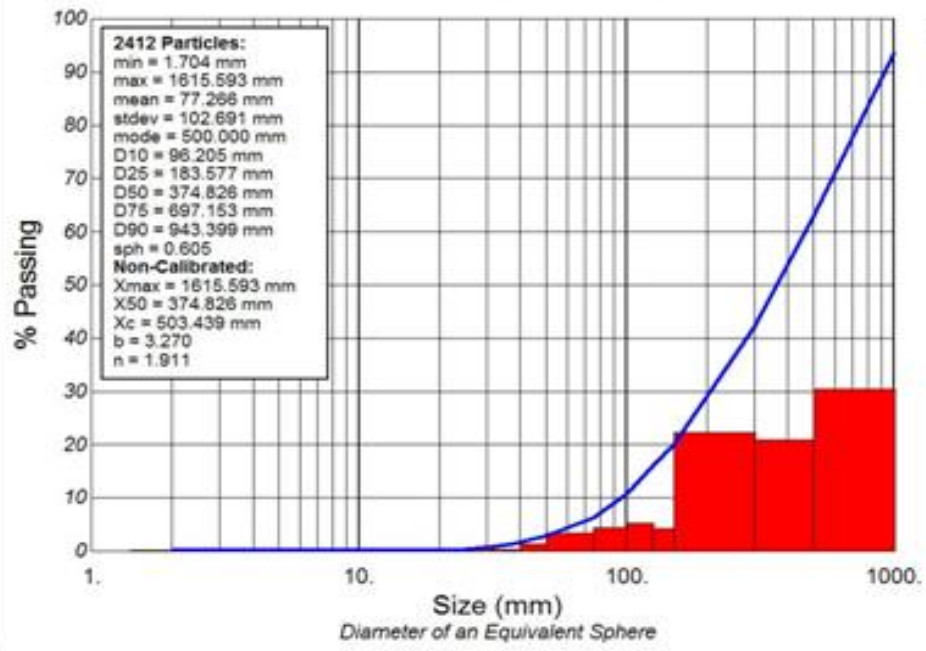

$\begin{array}{rr}\text { Size (mm) } & \text { \% Passing } \\ 1000.00 & 93.45 \% \\ 500.00 & 62.99 \% \\ 300.00 & 42.23 \% \\ 150.00 & 20.03 \% \\ 125.00 & 15.86 \% \\ 100.00 & 10.66 \% \\ 75.00 & 6.29 \% \\ 50.00 & 2.88 \% \\ 40.00 & 1.60 \% \\ 37.50 & 1.37 \% \\ 35.50 & 1.15 \% \\ 31.50 & 0.80 \% \\ 25.00 & 0.31 \% \\ 16.00 & 0.04 \% \\ 12.50 & 0.01 \% \\ 10.00 & 0.00 \% \\ 8.00 & 0.00 \% \\ 6.70 & 0.00 \% \\ 5.60 & 0.00 \% \\ 4.75 & 0.00 \% \\ 4.00 & 0.00 \% \\ 3.35 & 0.00 \% \\ 2.00 & 0.00 \% \\ 1.40 & 0.00 \% \\ 1.00 & 0.00 \% \\ 0.85 & 0.00 \% \\ 0.60 & 0.00 \% \\ & \end{array}$

Fig 4:- Netting, contouring, histogram and cumulative size curve view of fragmented block at Dongri Buzurg Mine, MOIL, India. 
VII. RESULTS

\begin{tabular}{|c|c|c|c|c|}
\hline PARAMETER & Image 1 & Image 2 & Image 3 & Average \\
\hline $\mathrm{D}_{10}$ & $86.199 \mathrm{~mm}$ & $98.411 \mathrm{~mm}$ & $96.205 \mathrm{~mm}$ & $93.605 \mathrm{~mm}$ \\
\hline $\mathrm{D}_{30}$ & $152.94 \mathrm{~mm}$ & $217.85 \mathrm{~mm}$ & $206.66 \mathrm{~mm}$ & $192.483 \mathrm{~mm}$ \\
\hline $\mathrm{D}_{60}$ & $300 \mathrm{~mm}$ & $486.66 \mathrm{~mm}$ & $468.75 \mathrm{~mm}$ & $418.470 \mathrm{~mm}$ \\
\hline
\end{tabular}

Table 4:- Average values of $\mathrm{D}_{10}, \mathrm{D}_{30}$, and $\mathrm{D}_{60}$ obtained from the WipFrag analysis.

Uniformity Coefficient $\left(\mathrm{C}_{\mathrm{u}}\right)$ is 4.47 indicating the size grain characteristic of the muckpile is very uniform.

Coefficient of Gradation $\left(\mathrm{C}_{\mathrm{g}}\right)$ is 0.945 indicating the distribution of fragments is mostly well graded.

\section{CONCLUSION}

Measurement of fragment sizes obtained in blasting is very important, particularly in case of blasting in ore body. Based on the fragment sizes obtained, blasting parameters can be re-designed to obtain the optimum results. Among the different methods of blast fragmentation measurement, Digital Image Analysis Technique was found to be one of the most effective tools and lesser time taking and more economic.

In the present study, fragmentation analysis was carried out using Wipfrag Software. The obtained results fr0m the individual analysis of the rock pile samples cannot be treated as perfect because the digital images taken f0r the analysis cann0t reveal the c0nditi0ns of fragmentation behind the muckpile surface. Calculation of Uniformity coefficient and Coefficient of gradation is simple and effective for the blast fragment appraisal. The Obtained results were thus much precise to predict the optimum blast parameters.

Wipfrag software was found to be very good for fragmentation analysis where measurement of blast fragment sizes can be easily carried out with very short interval of time. The desired blast fragment sizes can be achieved with this software.

\section{ACKNOWLEDGMENTS}

The authors are thankful to the Dongri Buzurg (MOIL) mine officials for providing necessary facilities during field investigations and Rock Excavation Engineering department, CSIR-Central Institute of Mining and Fuel Research, for helping with the image analysis using WipFrag software.

\section{REFERENCES}

[1]. Sharma, P.D., Blast Fragmentation Appraisal Means to Improve Cost-Effectiveness in Mines, Mining and Blasting wordpress Journal, 2010, pp.1-14.

[2]. Tekniska, H.,International Symposium on Rock Fragmentation by Blasting,Australasian Institute of Mining and Metallurgy, Society for Experimental Mechanics (U.S.), 2009, pp. 312-316.

[3]. Hartman, H.L, Mutmansky, J.M, Introductory to Mining Engineering, John Wiley \& Sons publications, second edition, New Jersey (US), 2002, pp. 421-430.
[4]. Singh, P.K, Sinha, A., Rock fragmentation by blasting, CRC press, Proceedings of $10^{\text {th }}$ international symposium on rock fragmentation by blasting, New Delhi (India), pt. 2013, pp. 10-18.

[5]. Pradhan, G.K, Ghose, A.K, Drilling and Blasting, MINTECH Publications, Mining Engineering Division, Mining Engineers' Association of India. New Delhi Chapter, 1996, pp. 32-36.

[6]. Annual Mining Symposium and the Annual Meeting of Minnesota Section, AIME, volume 28, University of Minnesota, pt. 1967, pp. 182-204.

[7]. Maerz, N. H., Palangio, T. C., Franklin, J. A., WipFrag image based granulometry system. In: Franklin, J. A., Katsabanis, P. D. (eds.), Measurement of blast fragmentation. Balkema, Rotterdam, 1996, pp. 91-98.

[8]. Singh, P.K. and Sinha, A., Rock Fragmentation by Blasting: Fragblast 10, CRC Press, New Delhi, 2012, pp. 32-36.

[9]. Maerz, N. H., Palangio, T. C. and Franklin, J. A., WipFrag image based granulometry system. Proceedings of the FRAGBLAST 5 Workshop on Measurement of Blast Fragmentation, Montreal, Quebec, Canada, 1996, pp. 91-99.

[10]. Cunningham CVB. The Kuz-Ram model for prediction of fragmentation from blasting. In: Proceedings of the first international symposium on rock fragmentation by blasting, Lulea, Sweden, 1983, pp. 439-454.

[11]. Terzaghi, K., Peck, R.B., Mesri, G., Soil Mechanics in Engineering Practice, $3^{\text {rd }}$ edition, John Wiley \& Sons publications, 1996, pp. 18-20.

[12]. Watson, I., Burnett, A.D., Hydrology: An Environmental Approach, CRC Press, 1995, pp. 113118. 